\title{
Se-Sn (Selenium-Tin)
}

\section{H. Okamoto}

[96Feu] obtained phase boundary data by DSC and XRD in the whole composition range ( 28 compositions between 10 and 90 at.\% Se) and calculated the Sn-Se phase diagram (Fig. 1) by optimization of their results together with thermodynamic data in the literature. The $\mathrm{Sn}$-Se phase diagram in [Massalski2] was redrawn from [86Sha], but it included speculative phase boundaries because experimental data were insufficient. Sn-Se crystal structure data are summarized in Table 1.

\section{Cited References}

77Ala: F.A.S. Al-Alamy, A.A. Balchin, and M. White, J. Mater. Sci., 12, 2037-2042 (1977).

78Wie: H. Wiedemeier and H.G. von Schnering, Z. Kristallogr., 148, 295-303 (1978).

79Wie: H. Wiedemeier and F.J. Csillag, Z Kristallogr, 149, 17-29 (1979).

86Sha: R.C. Sharma and Y.A.Chang, Bull. Alloy Phase Diagrams, 7(1), 68-72(1986).

96Feu: Y. Feutelais, M. Majid, B. Legendre, and S.G. Fries, J. Phase Equilibria, 17(1), 40-49(1996).

Table 1 Sn-Se Crystal Structure Data

\begin{tabular}{|c|c|c|c|c|c|c|}
\hline Phase & $\begin{array}{l}\text { Composition, } \\
\text { at.\% Se }\end{array}$ & $\begin{array}{l}\text { Pearson } \\
\text { symbol }\end{array}$ & $\begin{array}{l}\text { Space } \\
\text { group }\end{array}$ & $\begin{array}{c}\text { Strukturbericht } \\
\text { designation }\end{array}$ & Prototype & Reference \\
\hline$(\beta S n)$ & 0 & $t I 4$ & $14, / a m d$ & $A 5$ & $\beta S n$ & $\ldots$ \\
\hline 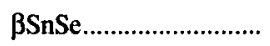 & 50 & $o C 8$ & $\mathrm{Cmcm}$ & $B_{\mathrm{f}}$ & $\mathrm{CrB}$ & 79Wie \\
\hline$\alpha \mathrm{SnSe}$ & 50 & $o P 8$ & Pnma & $B 16$ & GeS & $78 \mathrm{Wie}$ \\
\hline $\mathrm{SnSe}_{2}$ & 66.7 & $h P 3$ & $P \overline{3} m 1$ & $C 6$ & $\mathrm{CdI}_{2}$ & 77Ala \\
\hline
\end{tabular}

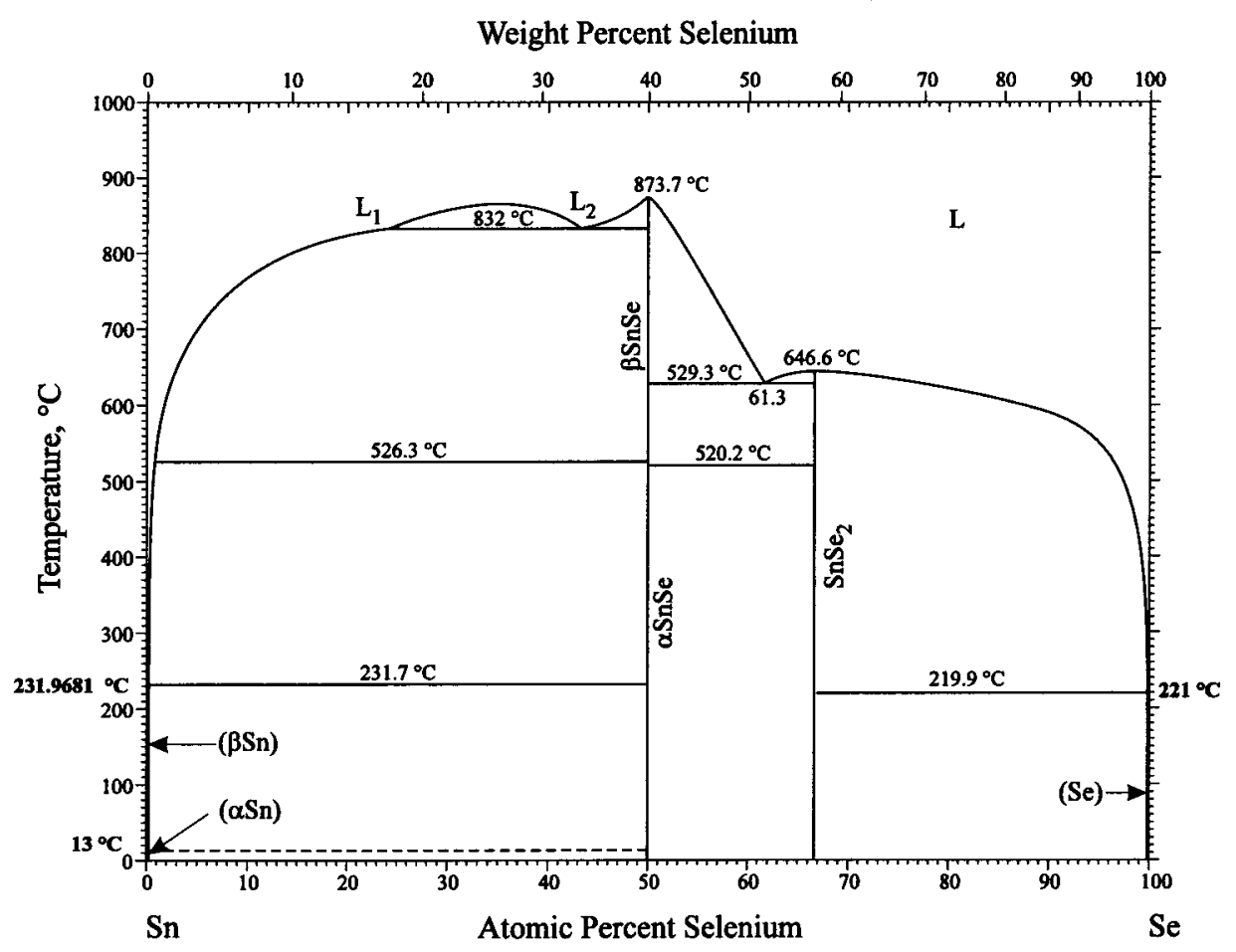

Fig. 1 The Sn-Se phase diagram. 